\title{
MOVIMENTOS SOCIAIS E COMUNITÁRIOS NO CAMPO DA SAÚDE COMO SUJEITOS E OBJETOS DE EXPERIÊNCIAS EDUCATIVAS.
}

\author{
MÁRCIA FARIA WESTPHAL*
}

\begin{abstract}
RESUMO: Tendências e modelos teóricos sobre movimentos sociais e educação foram analisados desde a década de 40 , no que respeita à participação das camadas populares na questão da saúde. Verificamos na atualidade a emergência de práticas que redefinem a relação entre Estado e Sociedade, possibilitando o posicionamento dos individuos como cidadãos com direito a saúde e melhores condições de vida. A população e os profissionais de saúde entretanto, vem confundindo saúde com assistência médica, os primeiros se colocando como consumidores de serviços e os segundos como fornecedores dos mesmo, desmobilizando as organizações populares para lutas mais amplas. A formação política e a informação sobre saúde à população são necessidades que se colocam para os profissionais de saúde, que assumiram um compromisso político com a população, sujeito do processo educativo e de saúde, de acordo com os principios do Sistema Único de Saúde. Três alternativas pedagógicas são apresentadas para o profissional que quer ultrapassar os limites de um processo educativo normativo, de preceitos de saúde, colocando os movimentos sociais como sujeitos das ações de saúde e educação: a pedagogia do conflito; a tendência libertária, que reúne defensores da auto gestão pedagógica; e a pedagogia crítica social dos conteúdos.
\end{abstract}

\footnotetext{
* Professor Associado do Departamento de Prática de Saúde Pública, da Faculdade de Saúde Pública da Universidade de São Paulo.
} 


\section{ORIGENS}

A reflexão sobre movimentos sociais, desenvolvimento comunitário, educação e saúde é fruto de uma história de produção teórica em torno do tema, onde a questão saúde entra como elemento complementar, como área de aplicação.

Estudos e trabalhos comunitários de caráter educativo no Brasil se iniciam na década de quarenta, após a segunda guerra mundial, como parte dos mecanismos de manutenção de hegemonia de duas grandes potências mundiais, que representavam o capitalismo e o socialismo: Estados Unidos e Rússia. A pobreza e o subdesenvolvimento dos países do terceiro mundo tornam-se um risco e um desafio para os paises capitalistas avançados. As agências internacionais, principalmente americanas, começaram a investir no desenvolvimento do pais, principalmente junto a comunidades rurais, com a inovação de técnicas agrícolas, com o objetivo de prevenir tensões sociais geradoras de movimentos populares. 0 intercâmbio de técnicos tornou-se freqüente e com ele o processo de inculcação ou reforço da ideologia capitalista no pais. Esses programas cresceram e se diversificaram envolvendo toda comunidade rural, na resolução de questōes de sobrevivência, saúde, educação, habitação, sempre dentro de uma perspectiva localista. ${ }^{1-2}$

Com um governo populista-desenvolvimentista e a abertura permitida por ele, a contradição tomou corpo e os investimentos feitos em nome da manutenção do capitalismo acabaram gerando conscientização e movimento. Neste momento foi possivel à alas dissidentes da Igreja iniciar trabalhos de base com a população excluída, residente em regiōes urbanas. Organizaram cursos de alfabetização que mais tarde se unificaram num Movimento Nacional de alfabetização, envolvendo comunidades que viviam em torno das paróquias ou 
mesmo em bairros das periferias. Outros grupos foram se organizando, também sob a influência da Igreja Católica, a Juventude Operária Católica, Juventude Estudantil Católica e outros. Intelectuais de esquerda ajudaram a reacender o movimento operário, reunindo os sindicatos na Confederação Geral dos Trabalhadores (CGT), e estudantes universitários na União Nacional dos Estudantes (UNE), com finalidade de defesa de seus direitos. Os programas, que começaram pautados por uma filosofia integradora, aos poucos foram crescendo, seus membros ampliando sua consciência localista e os agrupamentos se transformando em movimentos com força reivindicatória. Em 1964 a ameaça ao regime era tão grande que ocorreu o golpe e o governo militarista assumiu o país. ${ }^{1-}$ 2

Neste período anterior a ruptura da relação Estado-Sociedade, o envolvimento dos grupos populares com saúde foi somente indireto, sendo este um dos problemas decorrentes da situação geral de exclusão dos benefícios do desenvolvimento, em que a maioria da população se encontrava. Os profissionais de saúde entretanto, antes e durante o período de governo militar, mantiveram uma organização, sempre refletindo sobre os problemas de saúde e buscando melhores formas de organização para o Sistema de Saúde. Constituíram desde a década de 40, o chamado Movimento Sanitário, que assumiu várias formas e defendeu várias bandeiras até conseguir hoje a implementação do Sistema, que concretizou a Reforma Sanitária Brasileira. ${ }^{3}$ 


\section{OS NOVOS MOVIMENTOS SOCIAIS}

No pós-64 em função da supressão dos canais institucionais de expressão de interesses da população em relação ao Estado, surgem o que foi chamado de novos movimentos sociais: associações de moradores, movimentos por habitação e movimentos comunitários (CEBS). Assumem o significado da ação direta e autêntica das bases populares, com características autônomas, na luta por melhores condições de vida, mas com peculiaridades relacionadas às suas origens e comprometimento ideológico. $4-5$

Vários paradigmas tem procurado explicar a emergência desses novos modelos de movimentos sociais. Um deles, que tem sido utilizado por vários autores é dos movimentos sociais em contraposição com o Estado, em função da luta de classes. O Estado executor dos interesses da burguesia e do capital deve ser enfrentado, para que visualize os interesses do proletariado. Vários estudos foram feitos utilizando este paradigma e o próprio Estado procurou manter-se na defesa contra os movimentos. Entretanto, o tempo passou, as massas não fizeram a revolução e os estudiosos buscaram outros paradigmas explicativos. ${ }^{2}$

CASTELLS6, cientista social espanhol, estudando os movimentos por habitação no seu pais definiu movimentos sociais como "um sistema de práticas sociais contraditórias que colocam em questão a ordem estabelecida a partir de contradições especificas sobre a problemática urbana". A partir desta concepção e do referencial deste autor, foi possível explicar de forma mais convincente o aparecimento das organizações populares e seus movimentos de luta. $\mathrm{Na}$ realidade, grande contingente da população que saiu do campo para as cidades aos poucos foi sendo expulsa dos bairros centrais para periferia em que continuaram vivendo em precárias condiçōes de vida e privadas de equipamentos coletivos. Vários estudiosos, então, passaram a utilizar o paradigma das 
"contradições urbanas" para entender a eclosão dos movimentos. A partir deste referencial foram feitos os primeiros trabalhos sobre associações de bairro e luta pela sobrevivência e autonomia. Entre os estudos sobre os movimentos por equipamentos coletivos e saúde, especificamente na Zona Leste, o de $\mathrm{JACOBI}^{7}$ se destaca, por ser bastante ilustrativo da luta que vem ocorrendo na região por melhores equipamentos de saúde, entre outros.

SADER 5 , insatisfeito com os modelos explicativos já citados, buscou inspiração em CASTORIADES, filósofo social europeu, que colocou em dúvida a relação mecânica e direta entre as necessidades objetivas e a emergência da organização popular. SADER ${ }^{5}$, NUNES 8 e outros, partindo desta premissa, consideraram que problemas objetivos, as carências urbanas só se transformam em reivindicações, ao serem reinterpretadas pela estrutura simbólica, o imaginário do grupo social, que faz a mediação entre necessidades objetivas, necessidades sociais e a eclosão dos movimentos. Aos estudiosos que procuram entender a identidade dos movimentos SADER, muito imbuído destas idéias, recomendou: "OS que se poupam de uma análise especifica dos imaginánios próprios da população, vão perder o que os singulariza, vão escapar do principal". 5

\section{RELAÇÃO ENTRE ESTADO, MOVIMENTO E OS ARTICULADORES SOCIAIS}

Para $\mathrm{JACOBI}^{7}$, as relações entre o Estado e os Movimentos Sociais não eram mais exclusivamente de conflito contra algo que se desconhece. Para ele, o Estado precisou modificar-se apesar de continuar defendendo os interesses dominantes. Muitas vezes mesmo comprometido teve que negociar, atender, abrir espaço para a classe proletária. O Estado, segundo JACOBI "Não pode mais ser entendido como uma unidade monolítica a serviço de um projeto político invariável. mas deve ser visualizado como um sistema de permanente fluxo interno 
diferenciado sobre o qual repercutem demandas e contradições da sociedade civil" 7 .

BOSCHI ${ }^{9}$, um autor que se preocupou em conhecer melhor esta "caixa preta", o Estado, acha possivel uma relação mais próxima dos movimentos com o mesmo, defendendo o processo de institucionalização como uma necessidade. $\mathrm{Na}$ área da saúde VALLA \& STOTZ ${ }^{10}$, como $\mathrm{BOSCHI}$, defendem a participação popular regulada, nos aparelhos estatais, com caráter deliberativo. Estes devem ser os canais, que as camadas populares devem se utilizar para penetrar o campo de construção da teia de dominação e encontrar o caminho para exigir a parcela de bens e serviços de que tem sido alijadas, a partir da concretização da redistribuição dos mesmos.

Para aprofundar a análise do tema, movimentos sociais no campo da saúde como sujeito e objeto de experiencias educativas, diante das opçōes existentes, é importante marcar posição em relação à discussão sobre paradigmas explicativos.

. Incorporamos a idéia de contradições urbanas, como mobilizador de carências sociais e um fator importante para eclosão dos movimentos uma vez que "é sempre possivel relacionar processos sociais concretos a características estruturais". 6

Consideramos os movimentos como uma identidade social nova, diferente dos mecanismos clássicos de ação política, como diz SADER 5 , "sujeitos coletivos", "uma coletividade onde se elabora uma identidade e se organizam práticas, através das quais membros pretendem defender interesses e expressar vontades constituindo-se em lutas". 5 
- O Estado, na relação com os movimentos é contraditório. Caracterizase como defensor dos interesses das classes dominantes. Muitas vezes, entretanto, transforma-se em indutor de demandas sociais, mostra-se aberto às idéias de transformação e por motivos diversos, dentre os quais a tentativa de cooptação, abre-se à institucionalização dos movimentos, através da representação em organismos públicos.

. Não é possível esquecer na relação - Atores sociais e Estado - o papel relevante dos articuladores sociais. Estes têm tido sempre um papel aglutinador, às vezes orientados por determinados fins e pela sua própria sobrevivência, como foi e tem sido a Igreja Católica, que procuram dar um referencial comum as açōes dispersas, socializam e ajudam na reelaboração das carências, e na expansão do nivel de politização das demandas ao Estado. Foram e vem sendo estes os agentes da educação popular, expressando na sua ação várias tendências educacionais.

\section{SAÚDE, OS NOVOS MOVIMENTOS SOCIAIS E A INSTITUCIONALIZAÇÃO DA PARTICIPAÇÃO POPULAR}

Com a abertura política do país na década de 80 , as forças progressistas ascenderam ao poder para legitimar o processo de democratização do país. Como parte deste processo o Movimento Sanitário, associado aos movimentos populares em luta por equipamentos coletivos e aos grupos de profissionais de saúde, que iniciavam um movimento por condições mais dignas de trabalho, se reuniram em uma Plenária de Entidades, que passou a exigir a implantação do que se chamou "Reforma Sanitária Brasileira". 2 
Esta proposta baseava-se em princípios racionalizadores do atendimento à saúde, mas também objetivava a democratização das ações de saúde. Desde 1970 já havia abertura legal para a formação de Conselhos de Saúde, onde a população, organizada ou não em movimentos, poderia participar. Foi o primeiro momento onde este direito foi concedido. Mais tarde com a implantação das Ações Integradas de Saúde (AIS), outras aberturas foram dadas à participação no Sistema de Saúde. Para facilitar a integração do sistema curativo, de responsabilidade do INAMPS, com o preventivo, de responsabilidade do Ministério da Saúde, foi criada uma gerência compartilhada, interinstitucional, com a presença de representantes das instituições e da população, dando continuidade ao já iniciado processo de democratização das ações de saúde. Formaram-se então comissões de gerenciamento do Sistema, em cada nivel administrativo, compostas por representantes de todas as instituições envolvidas no processo e da população. As Comissōes formadas nos vários niveis administrativos, foram: Comissão Institucional de Saúde (CIS), Comissão Regional Interinstitucional de Saúde (CRIS), Comissão Municipal Institucional de Saúde (CMIS) e a Comissão Local Interinstitucional de Saúde (CLIS).

Os intelectuais articulados no Movimento Sanitário, com estas experiências em andamento conseguiram realizar a 8a. Conferência Nacional de Saúde, onde estes principios foram extensamente discutidos e afinal uma proposta de Reforma foi formulada para ser institucionalmente legalizada. A Constituinte estava iniciando seus trabalhos e a ela a proposta foi encaminhada. Apesar de modificada em aspectos fundamentais, foi aprovado o Capitulo de Saúde na Constituição promulgada em 1988, após uma pressão muito forte exercida pela população e profissionais organizados na Plenária já mencionada. A proposta de "Participação da comunidade" foi então oficialmente aprovada. 
Atualmente a existência de Conselhos Municipais de Saúde é uma obrigação legal uma vez que a transferência de recursos federais para o Municipio só pode ser feita através dele. A idéia é que a população participe do planejamento de saúde e inclusive da distribuição de recursos enviados ao seu Município. Essa abertura não foi uma concessão do Estado, foi uma conquista dos movimentos organizados da saúde e sua manutenção e ampliação dependerá uma vez mais do enfrentamento deste Estado contraditório, que usará de mecanismos para evitar que a população organizada amplie seu espaço e sua interferência nas políticas públicas. 2

A implantação do Sistema Único de Saúde (SUS), não implica que não haja mais necessidade do movimento sanitário para lutar por ele. A própria incorporação de pessoas do movimento no Aparelho do Estado foi feita para garantir a continuidade do processo, a ampliação do espaço de discussão e a implantação das medidas democratizantes propostas. Entretanto, o que aconteceu? Essas pessoas se afastando do movimento "deram as costas para suas propostas", assumindo a estratégia burocratizante racionalizadora do Estado e dando com isto "as costas para a população e para os movimentos populares". Isto prova que é importante a continuidade de um movimento autônomo, independente do Estado, comprometido com os interesses das classes populares, que possa continuar pressionando muitas vezes contra propostas de membros do próprio movimento.

Se a ascensão ao poder tem desviado os intelectuais de seus compromissos, que dirá a população, que assume o papel de representante de um bairro ou de uma associação em um Conselho ou uma Comissão Gestora de Distrito ou Unidade Local de Saúde ? Tem sido facilmente cooptada.

A proporcionalidade da participação popular nas Comissões Interinstitucionais favorecia a cooptação. Era fácil aos administradores 
acostumados a tomar decisões sozinhos, eliminar a influência da população nas suas deliberações. Com raras exceções, todos os representantes populares se submetiam às argumentações dos doutores "donos do saber". Muitas vezes recebiam em troca "favores", um atendimento especial para seu filho, seu vizinho ou algo semelhante. A política da dominação, do favor, clientelista, sempre orientou a ação destes Conselhos.

Os Conselhos de Saúde foram revistos em termos da legislação e agora o pareamento da representatividade é diferente. A população é composta por $50 \%$ dos membros e $25 \%$ da administração e $25 \%$ dos funcionários. Mesmo assim, na maior parte das vezes, tem se constituido por preceito legal, só para justificar, ou legitimar a verba recebida, sendo que na realidade não existem. Muitos deles reúnem-se após a eleição e para eleger nova diretoria. A maior parte de seus membros não tem assumido seu papel, como o de alguém que desempenha uma função pública para defender os interesses da população, participando do planejamento de ações, que venham a melhorar suas condições de vida e saúde. A grande maioria não é convocada para discutir uma pauta e muito menos deixam gravada em atas suas decisões. A ação dos movimentos populares não tem se dirigido para a utilização deste canal de participação, não tem apoiado seus membros, nem exigido deles contas sobre o resultado de sua representação. Estes mesmos continuam frágeis, com uma ação fragmentária, por bairro, reivindicatória e direta com os representantes do poder público: deputados, senadores e prefeitos, se utilizando mais dos canais tradicionais de reivindicação, que dos novos canais recém-instituídos. Com isso a ação dos movimentos não unificada, é frágil e desalentadora e a ação dos representantes da população nos Conselhos é, na maior parte das vezes, clientelista e sem força de transformação.

O coletivo, como solução para problemas que afligem as pessoas, se não acabou está em descrédito. "Os muros caíram e com eles as utopias."4 
Mas será que todo este esforço, de educar (educere =, tirar para fora), de trabalhar "a cidadania coletiva", de nada valeu?

\section{EDUCAÇÃO, SAÚDE E MOVIMENTOS SOCIAIS}

O que os profissionais de saúde e mais especificamente os educadores de saúde poderiam fazer para utilizar a energia dos nossos movimentos sociais para que as condiçōes de vida e saúde das populações nele envolvidas se transformem, tornando mais suportáveis as contradições urbanas?

Retomando a história das instituiçōes de Saúde Pública, no âmbito das instituiçōes públicas de saúde, das demais instituições como escolas, fábricas, é possivel caracterizar as diferentes concepçōes de educação predominantes em cada um dos momentos. Desde os primórdios, no país da mesma forma que em outros paises, as instituiçōes de saúde e educação serviram à hegemonia das classes dominantes, no sentido de obter consenso sobre as concepçōes de saúde e educação que elaboravam. No início do século a "era bacteriana" precisava ser consolidada, de acordo com a direção autoritária da sociedade, reforçada por concepções de educação essencialmente tradicionais. Para vencer os desvios da sociedade e conter a população, era preciso vencer a ignorância, aspecto naquele momento essencial para controle de comportamentos e portanto a razão determinante das doenças e das pestes. Notícias foram publicadas na imprensa sob a forma de "conselhos para o povo", folhetos distribuídos como forma de esclarecimento, almanaques com ilustrações para atingir os analfabetos, sempre apelando para 0 medo. De forma complementar, ministravam-se nas escolas noções de higiene pessoal e da habitação para o "povo ignorante". A articulação entre a educação comc transmissão de conhecimentos e saúde como atividade policialesca, controladora, atendeu aos interesses da oligarquia cafeeira. ${ }^{2-11-12}$ 
Nos anos 20, em resposta às necessidades emergentes de controle da população, a direção da sociedade foi organizando instituições voltadas para a assistência à saúde e à educação em saúde, a partir do modelo importado dos Estados Unidos, sob inspiração "higienista", prescindindo então do argumento policialesco. Centros de saúde foram criados como base logistica para a educação sanitária. Coincidentemente, no mesmo periodo ocorreram mudanças nas propostas educativas, a partir da introdução do "escolanovismo" no Brasil, como um movimento democrático de reforma pedagógica, que afirmava a crença no poder da educação como um instrumento de equalização social. ${ }^{13}$ Com referência à pedagogia tradicional deslocou o eixo da questão pedagógica do intelecto para o sentimento, do lógico para o psicológico, das cognições para os métodos, justificando a necessidade de formação de um profissional que não conhecesse só o conteúdo de saúde, mas principalmente os métodos educativos. ${ }^{13}$ Com esta justificativa deu origem ao Curso de Formação de Educadores Sanitários, que se responsabilizariam pelo desenvolvimento de ações educativas de saúde, nos Centros de Saúde e Escolas. Essas atividades inovadoras no campo da saúde e educação pretendiam eliminar desvios sem questionamentos da ordem e da moral, nem mesmo das relações sociais que determinam o processo saúde e doença. 2$10-11$

A década de $30 / 40$ foi marcada pela transferência do poder dos produtores de café para os industriais. A forma de capitalismo existente era o que podemos chamar de "capitalismo selvagem", que logo provocou reaçōes no operariado explorado, dando origem ao Movimento Operário no Brasil, uma luta organizada para obtenção de preceitos legais, que pudessem garantir sua proteção. Á Educação em geral e a Educação em Saúde em particular, ficou mais uma vez encarregada de domesticar e moralizar este proletariado urbano emergente e manter a raça higida, norteando-se por principios "eugênicos". O autoritarismo do Estado Novo tornava fértil estas idéias fascistas que inspiravam o 
trabalho educativo realizado nos postos de saúde e nas escolas, sendo a esterilização uma das medidas preconizadas para defender a raça dos defeitos hereditários. $2-11-12$

Foi novamente nos Estados Unidos que emergiu, na década de 40, uma nova concepção do processo saúde doença, ressurgindo a educação em saúde com um novo discurso. Foi a época do Sanitarismo-Desenvolvimentista ${ }^{3}$, já mencionado, que propiciou uma revisão da forma de aplicação dos princípios escolanovistas, então em clima de abertura, populista, e com o processo saúdedoença sendo explicado pela tríade ecológica (homem-hospedeiro-ambiente), incluindo ações em relação às comunidades para integrá-las ao desenvolvimento. $A$ educação, situada no âmbito da instituição de saúde, se configurava como meio, complemento e suporte das ações médico sanitárias, visando sua maior eficiência. Persuadir a população ignorante, a fazer o que o especialista achava certo, era a idéia vigente na maioria dos programas de saúde, onde ela se incorporava. Continuava a reduzir-se a transmissão de conteúdos desnivelados das condições de vida da população, melhor definidos como Propaganda Sanitária, baseada ainda em princípios escolanovistas, que reconhecia que a educação deveria basear-se na ciência e em métodos ativos, "superando o empirismo grosseiro e as tendências intelectualistas". 14 Fez parte dos programas de extensão rural já mencionados, assumindo a forma "localista'"' de abordagem dos problemas, longe de visualizar as raizes estruturais e econômicas dos problemas de saúde. $2-11$

No periodo de 64 a 85 experienciamos novamente a ditadura, que privilegiou o modelo privatista. O pagamento por produção, o incentivo à utilização de alta tecnologia, facilitou a corrupção, trazendo gradativamente sérios problemas à estrutura de atendimento à população, já prejudicada pela aumento da desigualdade na distribuição da renda existente no país. Em relação à educação aparecia o "escolanovismo" desgastado. Antes da ditadura surgiram tentativas de 
desenvolver uma "Escola Nova Popular", cujo maior expoente foi Paulo Freire, 14 que teve influência marcante em alguns segmentos profissionais da Saúde Pública. Por outro lado, em um governo autoritário, altamente repressivo e centralizador, ficava difícil pensar a educação dentro de uma nova racionalidade que não a do Estado. A busca da eficiência na educação, já não mais acreditada possivel via Escola Nova, coloca os educadores diante de uma nova teoria, o Tecnicismo. A partir do pressuposto de neutralidade cientifica e inspirada nos princípios de racionalidade, eficiência e produtividade, a educação e a educação em saúde, apoiadas no novo referencial revêem sua forma de encarar o processo educativo, para torná-lo mais objetivo e operacional. ${ }^{15}$ Ao lado desta tendência, na Universidade onde o controle ideológico foi aos poucos diminuindo, no final da década de 70 , recomeçaram a debater textos críticos, que chamavam atenção para o papel reprodutor da educação em relação à sociedade e ensaiavam programas de medicina comunitária com participação popular a exemplo do que vinha ocorrendo na América Latina em geral.

Com o inicio da democratização, os educadores da mesma forma que os sanitaristas, intensificaram a discussão na busca de novos paradigmas para nortear a atividade educativa, em todos os setores onde ela se institucionaliza.

Respondendo à questão inicial sobre como os educadiores poderiam colaborar com os movimentos, para que estes pudessem ampliar as energias utilizadas na luta por melhores condiçōes de vida e saúde propomos algumas recomendações:

1. Há necessidade de rever e optar por uma abordagem educativa que norteie os processos educativos das açóes de saúde.

Três linhas tem sido muito discutidas nos meios acadêmicos, dentro de uma perspectiva histórico-estruturalista e critico-construtivista, diferente das 
anteriormente utilizadas, que considera a sociedade dividida em classes sociais em função da desigual inserção no processo produtivo. Uma delas é a Pedagogia Libertadora, mais conhecida como de Paulo Freire, com as atualizações que nela foram feitas, também chamada Pedagogia do Conflito, por privilegiar como instrumental educativo, o desvelamento das contradições e conflitos da sociedade. A Tendência Libertária, que reúne defensores da autogestão pedagógica e a Pedagogia Crítica Social dos Conteúdos, que acentua a primazia dos conteúdos em confronto com as realidades sociais, são as outras duas opções. 13-14

Um aspecto importante a ser ressaltado é, seja qual for a opção pedagógica, que o processo educativo ocorre em dois momentos e a mesma visão de educação deverá pautar ambos, para que o processo não seja prejudicado por incoerências teórico-práticas. Esses momentos são:

A aprendizagem informal que decorre das experiências vividas: em contato com representantes do poder instituído; em contato com as burocracias estatais que tentam diminuir o seu poder legalmente instituido; em atividades de pressão realizadas para manifestar suas posiçōes e reivindicações; em contato com as assessorias, que ajudam a interpretar os determinantes dessas ações e os fatores que interferem nas condições de vida e saúde. A relação do Estado e, no nosso caso do Sistema de Saúde com os movimentos, é complexa; a conquista de qualquer demanda popular é muito difícil e desgastante para a população que precisa lidar com as contradições que o Estado encena. A aproximação de seus profissionais em certos momentos, o distanciamento e a rejeição que o movimento enfrenta quando procura as organizações estatais e seus representantes; os mecanismos que utiliza para convencer a população acostumada a passividade, ao paternalismo e ao clientelismo a reagir e a se unir; a própria relação entre os movimentos é altamente educativa para os membros das organizações populares. 
O resultado desta aprendizagem é uma formação integral, que fornece força e instrumental prático para a luta; que possibilita competir de forma menos desigual com as autoridades constituidas que querem, através de entraves burocráticos, mascarar o poder que a população conseguiu legalmente, de deliberar junto com as autoridades competentes sobre os assuntos de saúde.

A aprendizagem formal, através de Cursos de Formação Política, nos quais se oferecem experiências de aprendizagem programadas, que possibilitem a interpretação e o desvelamento da realidade pela população, que passa a ter consciência dos determinantes do processo saúde-doença. Propiciam ainda o acesso a informações instrumentais sobre gerenciamento de recursos para a saúde, definição de prioridades, organização e eficiência dos serviços de saúde.

O resultado é o acesso à informação necessária para poder trocar informações com os técnicos, com quem deverão compartilhar a responsabilidade pelo planejamento dos serviços de saúde, como cidadãos.

Nos dois momentos, utilizando qualquer uma das três opções pedagógicas, a participação dos individuos como sujeitos do processo é fundamental, pois a verdadeira educação não é o ato através do qual um sujeito transformado em objeto recebe dócil e passivamente os conteúdos que o outro lhe impõe. É pelo contrário uma aço que exige a presença curiosa do sujeito, cidadão, em face do mundo. Demanda uma busca constante, reflexão critica de cada um sobre $o$ fato de conhecer para evidenciar os condicionamentos a que 0 ato está submetido.

2. É necessário resolver um problema de enfoque, conforme sugere LEFÉVRE16: Os atores sociais, não profissionais, com os quais o Sistema de Saúde vai se relacionar e com quem pretende desenvolver processos educativos é o "usuário do serviço, consumidor de consultas, de 
medicamentos e outras práticas" ou é " o cidadão, pleno de direitos e deveres para com a coletividade, da qual participa"?

Uma ou outra opção tem implicações sérias para educação em saúde e para a ação dos serviços diante dos movimentos sociais e da população como um todo.

Se optarmos pela lógica do consumo, considerando saúde como uma mercadoria a ser negociada, trocada, estaremos contribuindo para manter a dependência da população e nos colocando numa posição superior de classe, e mantendo diante da representação popular, uma relação puramente interclassista, imobilista quando comparada aos esquemas anteriores.

Se formos analisar as experiências dos Conselhos que conhecemos e que são os canais abertos à participação dos movimentos, encontramos entre os administradores e profissionais de saúde, a concepção de "saúde-mercadoria". As reuniões dos Conselhos tem um grande espaço temporal para os "informes", que são comunicações de atitudes tomadas, suas justificativas, para conseguir o referendo popular. O tempo que sobra, é utilizado para ouvir alguma reivindicação da população. Os representantes de movimentos, mesmo os mais politizados se mantém em uma posição de fiscais da "venda da mercadoria" e portadores dos recados das organizações populares que desejam medicamentos, mais e melhor assistência médica, cuidados mais especializados, ambulâncias e coisas semelhantes. As insatisfações se regem pela lógica de direitos do consumidor e se restringem a demora para conseguir um atendimento, problema na relação profissional-cliente, falta de medicamento, médico não cumpre horário e coisas semelhantes.

Dificilmente deixam a esfera reivindicatória e assumem a proposicional, e nunca são ajudados a visualizar um novo paradigma de atuação do Sistema, a 
Vigilância à Saúde em vez do de Assistência, conforme a filosofia de alguns defensores da Reforma Sanitária. ${ }^{3}$

Se por outro lado tentarmos mudar nossa ótica e reencontrar o cidadão com direito a melhores condições de vida e saúde, vamos precisar sair de dentro do serviço e nos aproximar do contexto de vida da população servida por ele.

Os profissionais de saúde procurarão se aproximar dos movimentos sociais "captar sua dinâmica explicando-os pelas condições objetivas e subjetivas que os envolvem" 5 e trabalhar junto com eles como fizeram outros articuladores sociais, ligados aos movimentos e que já tivemos oportunidade de mencionar. ${ }^{7}$

\section{Mesmo tendo tomado posição diante dos dois questionamentos} anteriores é necessários cuidarmos da nossa contradição interna.

A educação persuasiva, a que submetemos a população no passado está presente entre nós até hoje. Os que se utilizam dela, difundem conteúdos sem revelar ou desvendar as contradições implícitas nos mesmos.

Muitos profissionais de saúde em todo mundo, tem se aproximando das populações, se dispondo a trabalhar com elas, se propondo a oferecer a informação à que têm direito, e respeitando o direito que têm de dispor de sua saúde/doença. Alguns entretanto, em vez de educar, desrespeitam ou aberta ou sub-repticiamente seu direito de decidir seus destinos. Modelos educativos considerados progressistas, que envolvem variáveis sociais, culturais, estudos de liderança dos mais simples aos mais complexos, tem reincorporado modelos de persuasão.

Os responsáveis por estes projetos tem se enganado, sendo informados por uma visão do processo educativo em que está implícita a ação de levar, 
transferir, entregar, depositar algo em alguém, dentro de uma conotação mecanicista. 2 o iluminismo de que se tem envolvido muitos profissionais de saúde, os tem impedido de visualizar, que a educação para a cidadania só se fará a partir das categorias populares, do seu universo simbólico e vocabular e não de uma forma outorgada através de intervenções externas. Neste sentido a educação tornar-se-á expressão de processos reais de constituição e formação do povo como sujeito político.

Olhando de outro ângulo, encontramos outro exemplo da dificuldade que têm os profissionais, de ser coerentes com suas propostas. Alienam-se em suas Unidades de Saúde ou na qualidade de "progressista", envolvendo-se em pesquisas acadêmicas na qual ele é o centro impulsor. Utilizam-se da população, de suas carências, para produzir trabalhos técnicos, que lhes dê visibilidade diante da comunidade científica. Invadem o campo popular, apropriam-se da energia latente da população, que é tratada como material de uso e ainda colocam-se como aquele que deve ficar distante, porque "teme o povo" ou resolve tudo "pelo povo". 2

Persuasão que devemos evitar, não sei se sempre conseguiremos, é a responsável pelo que chamamos invasão cultural, manipulação e messianismo, que se opõe à afirmação do homem como sujeito e como cidadão.

A educação que defendemos em termos de saúde é transformadora, junto aos grupos populares. Como emissária do SUS, tem outro objetivo, pretende transformar o mundo "com a população".

A educação que estamos aqui defendendo em relação aos movimentos populares, dentro do referencial do SUS, é a que considera a influência da estrutura social sobre os fluxos de comunicação, despertando a consciência dos determinantes das condições de saúde. O caminho é o diálogo, o trabalho conjunto, contra o assistencialismo e a domesticação. $O$ desvelamento, do que tem sido 
ocultado dos grupos populares e que evitou, ou limitou $\circ$ alcance de suas organizações, é provocado pela problematização na busca dos significantes e dos significados.

$\mathrm{Na}$ verdade este tema que estamos aqui tratando não é nada simples. Somente um educador ingênuo não percebe de antemão as armadilhas que estão envolvidos no tratamento da questão.

Uma empreitada como esta, de realizar um trabalho educativo junto aos movimentos sociais ou colaborando para a inserção de seus membros na instituição de saúde, como cidadãos capazes de defender seus direitos é muito importante, porém uma tarefa de gigantes, preparados teoricamente, com vivência prática, capacidade de reflexão e trabalho conjunto e grande comprometimento com as camadas populares da população.

Muitos têm desistido ou desacreditado da educação, depois de um momento de supervalorização da mesma, desanimados com a luta para mudar esta cultura política, sedimentada, tão difícil de mudar, tão carregada de vicios, hábitos e valores seculares: clientelismo, tutela, subalternidade e outros.

Devem ter esquecido do que FREIRE recomendou: "A transformação da educação não pode antecipar-se à transformação da sociedade, mas essa transformação necessita da educação". 17

A cidadania não se construiu por decreto, ao ser promulgada a Constituição Federal de 1988, mas com esta vitória surgiram novos espaços para esta se desenvolver, utilizando o argumento jurídico, como fundamento orientador de novas formas de agir. 
Segundo $\mathrm{GOHN}^{4}$, os efeitos da educação popular, na relação com os novos movimentos sociais, após a abertura democrática, se não conseguiram transformar, conseguiram resultados morais importantes. Instauraram uma nova racionalidade social, uma conscientização popular que deverá interferir na cultura política do país no próximo século: "o povo, os cidadãos, os moradores, as pessoas, ... tem direito a participar das questóes que Ihe dizem respeito".

Os novos espaços demarcados de participação, dos quais os Conselhos de Saúde são um exemplo, a nova postura da sociedade civil da qual fazem parte alguns segmentos de governantes e governados, que já consideram como norma de ação, a divisão do poder de decisão nestes espaços, são alguns destes saldos que estão ai para se multiplicar.

\section{REFERÊNCIAS BIBLIOGRÁFICAS}

1. AMMANN, S. B. Ideologia e desenvolvimento de comunidade no Brasi. $5^{a}$ ed. São Paulo, Cortez \& Morais, 1985.

2. WESTPHAL, M. F. Políticas municipais de saúde e participação popular: o caso de Cotia e Vargem Grande Paulista. São Paulo [Tese de Livre Docência Faculdade de Saúde Pública da USP].

3. TEIXEIRA, S. M. F. Antecedentes da reforma sanitária brasileira. Rio de Janeiro, Escola Nacional de Saúde Pública, Programa de Educação Continuada, 1988.

4. GOHN, M. G. M. - Movimentos sociais e educação. $2^{\text {a }}$ ed., São Paulo, Cortez, 1994. (Questões da época v.5)

5. SADER, E. Quando novos atores entram em cena (experiência de luta dos trabalhadores da Grande São Paulo, 1970 - 1980). Rio de Janeiro, Paz e Terra, 1988.

6. CASTELLS, M. Cidade, democracia e socialismo. Rio de Janeiro, Paz e Terra, 1980. 
7. JACOBI, P. Movimentos sociais e políticas públicas. São Paulo, Cortez, 1989.

8. NUNES, E. Carências urbanas, reivindicações sociais e ideais democráticos. Lua Nova, (17): 67-91, 1989.

9. BOSCHI, R. R. A arte da associação: política de base e democracia no Brasil. São Paulo, Vértice/Instituto Universitário de Pesquisas do Rio de Janeiro, 1987.

10. VALLA, V. V. \& STOTZ, E. N. Participação popular e saúde. Petrópolis, CDDH/CEPEL, 1989.

11. MELLO, J. A. C. Educação sanitária: uma visão crítica. Cad. CEDES, (4):28-43, 1987.

12. OSHIRO, J. H. Educação para a saúde nas instituições de saúde pública. São Paulo, 1988. [Dissertação de Mestrado - Pontifícia Universidade Católica de São Paulo].

13. FREITAG, B. Escola, estado e sociedade. $4^{a}$ ed. São Paulo, Ed. Moraes, 1980.

14. GADOTTI, M. Pensamento pedagógico brasileiro. $2^{a}$ ed., São Paulo, Ed. Ática, 1988.

15. CANDEIAS, N. M. F. Evolução histórica da educação em saúde como disciplina de ensino na Faculdade de Saúde Pública da Universidade de São Paulo 1925-1967. Rev. Saúde Pública, 22: 347-65, 1988.

16. LEFÉVRE. F. Contribuição para o entendimento de uma área nebulosa do SUS. São Paulo, 1992. [Trabalho apresentado em reunião da ABRASCO]

17. FREIRE, P. Educação e mudança. Rio de Janeiro. Paz e Terra, 1979. 